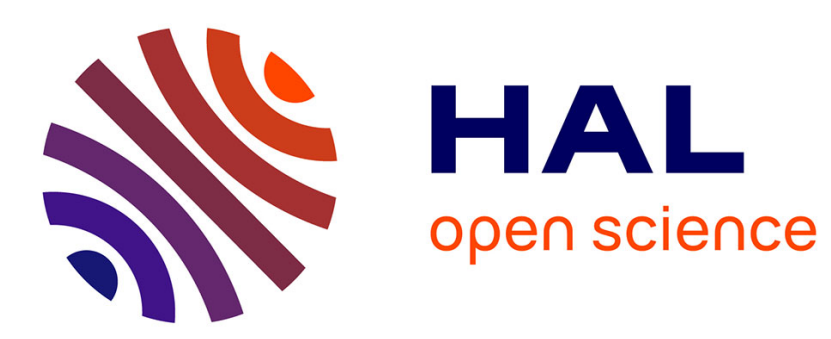

\title{
Influence of annealing duration on properties of AlLiCuMg thin-walled extruded shapes
}

\author{
V. Ocenásek, M. Slámová, K. Sperlink
}

\section{To cite this version:}

V. Ocenásek, M. Slámová, K. Sperlink. Influence of annealing duration on properties of AlLiCuMg thin-walled extruded shapes. Journal de Physique IV Proceedings, 1993, 03 (C7), pp.C7-219-C7-225. 10.1051/jp4:1993733 . jpa-00251976

\section{HAL Id: jpa-00251976 https://hal.science/jpa-00251976}

Submitted on 1 Jan 1993

HAL is a multi-disciplinary open access archive for the deposit and dissemination of scientific research documents, whether they are published or not. The documents may come from teaching and research institutions in France or abroad, or from public or private research centers.
L'archive ouverte pluridisciplinaire HAL, est destinée au dépôt et à la diffusion de documents scientifiques de niveau recherche, publiés ou non, émanant des établissements d'enseignement et de recherche français ou étrangers, des laboratoires publics ou privés. 


\title{
Influence of annealing duration on properties of $\mathrm{AlLiCuMg}$ thin-walled extruded shapes
}

\author{
V. OČENÁŠEK, M. SLÁMOVÁ and K. ŠPERLINK \\ Innovation Technological Center, Research Institute for Metals, 25070 Odolena Voda, Czech Republic
}

\section{INTRODUCTION}

Annealing at higher temperatures of lithium containing aluminium alloys is accompanied by lithium depletion of the surface layer. In consequence, the change of the chemical composition in this layer leads to a change of material properties. The layer thickness depends on annealing temperature and annealing duration. Lithium depletion of the surface layer was investigated in the framework of a model experiment aimed to evaluate the effect of heat treatment parameters on the properties of thin-walled extruded shapes.

\section{II . EXPERIMENTAL}

An experiment was carried out to investigate the influence of annealing duration on mechanical and fatigue properties. Aluminium-lithium alloy Al2.6Li1.9Cu0.9Mg0.1Zr L-shape extrusions of dimensions $44 \times 25 \times 2 \mathrm{~mm}$ were used as experimental material. The material was solution-heat-treated at $530^{\circ} \mathrm{C}$ for $20 \mathrm{mi}-$ nutes and for 10 hours; annealing in salt bath and in air was performed. In order to assess the effect of small plastic deformatione on properties after annealing the material was plastically deformed by stretching of rate $\theta$ and 5 percent. After a two stage artificial ageing $\left(150^{\circ} \mathrm{C} / 4 \mathrm{~h} .+170^{\circ} \mathrm{C} / 18 \mathrm{~h}.\right)$ tensile tests. hardness HB 2.5/62.5 measurements, resistometrical measurements on the specimen surface and fatigue tests were performed. Fatigue loading with $R=0, \sigma_{\text {mar }}=130 \mathrm{MPa}$ and $190 \mathrm{MPa}$ and $K_{t}=2.6$ and 1.1 resp., was used. The intensity of lithium depletion at different depth under the surface was determined by measuring microhardness $H V 0.05$ on polished metallographic specimens, representing a cross section of extruded shapes, at different distances from the extrusions surface. 


\section{RESULTS}

Plots of microhardness values vs distance from specimen surface for materials annealed for 10 hours in salt bath and in air with zero plastic deformation are given on Fig. 1. The Li-depleted layer was $400 \mathrm{um}$ thick, the microhardness immediately at the surface was twice lower in comparison with the microhardness in material volume. The microhardness curves of specimens annealed in salt and in air were similar thus the effect on depletion intensity of both annealing media compared is the same. Plots of microhardness values vs distance from specimen surface for materials annealed in air for $20 \mathrm{~min}$. without any subsequent plastic deformation and resp. plastically deformed (5\%) are given on Fig. 2. For both cases the Li-depleted layer thickness was only $50 \mathrm{um}$, the microhardness immediately at the surface represented again $50 \%$ of the value in the unaffected material.

The results of tensile tests, HB hardness measurements, fatigue tests and resistometrical measurements are summarized in Tab. 1. Values of strength $R_{m}$, yield stress $R_{p o} 2$, hardness $H B$ $2.5 / 62.5$ and electrical conductivity as a function of annealing and deformation parameters are plotted on Fig. 3 and 4 . Fatigue curves as a function of heat treatment parameters are given on Fig. 5. The lithium depletion of the surface zone resulted in a degradation of mechanical properties of 8 to $10 \%$ for the specimens annealed for 10 hours with respect to the values for specimens annealed for $20 \mathrm{~min}$. The yield stress degradation was more marked than the strength degradation. The hardness decrease and the electrical conductivity increase were also a consequence of the lithium depletion of the surface layer. From the experimental results the effect of the annealing medium on mechanical properties is not evident, on the contrary the effect of the deformation preceding the artificial ageing is significant.

Fatigue tests showed that the lithium depletion of the aurface layer does not influence the fatigue behaviour of the material after a long-termed solution-heat-treatment at $530^{\circ} \mathrm{C}$. The effect of lithium depletion was not proved by fatigue test on specimens with a central hole $\left(K_{t}=2.6\right)$ for all variants. However, the results of the the testa on specimens with stress 
concentration factor $K_{t}=1.1$ showed a small decrease of the mean value of fatigue life. However, considering the data scatter, that decrease falls on the limit of demonstrability.

\section{CONCLUSIONS}

Annealing for 10 hours resulted in the formation of a depleted layer 400 um thick, whereas the depleted layer thickness of eamples annealed for $20 \mathrm{~min}$. was lese than $100 \mathrm{um}$. The depleted layer thickness is not influenced by the annealing medium - it was almost the same for both media used. The experimental results for 10 hours annealing duration showed a decrease in strength and hardness, the decrease in elongation was not significant. Thus, the observed changes in properties result from the surface layers lithium depletion which leads to a decrease in etrengthening phases amount. For $k_{t}=2.6$ annealing duration did not influence fatigue properties, for $K_{t}$ $=1.1$ a weak decrease in mean fatigue life for gameles annealed for 10 hours was observed. Mechanical and fatigue properties were affected the most markedly by the omall plastic deformation preceding artificial ageing.

Tab. 1 Mechanical and fatigue properties and conductivity of heat treated extruded shapes

\begin{tabular}{|c|c|c|c|c|c|c|c|c|}
\hline medium & \multicolumn{4}{|c|}{ salt bath } & \multicolumn{4}{|c|}{ air } \\
\hline duration [min.] & 20 & 600 & 20 & 600 & 20 & 600 & 20 & 600 \\
\hline deformation $[\%]$ & $\theta$ & $\theta$ & 5 & 5 & $\theta$ & $\theta$ & 5 & 5 \\
\hline$R_{m} \quad[\mathrm{MPa}]$ & 460 & 424 & 495 & 453 & 453 & 418 & - & 479 \\
\hline $\mathrm{R}_{P 0.2}[\mathrm{MPa}]$ & 356 & 323 & 433 & 396 & 370 & 330 & - & 425 \\
\hline$A_{H}[\%]$ & 5.1 & 5.0 & 4.4 & 3.8 & 4.7 & 4.4 & - & 3.8 \\
\hline $\mathrm{HB}[1]$ & 117 & 89 & 121 & 99 & 114 & 98 & 128 & 114 \\
\hline cond. $\left[\mathrm{MSm}^{-1}\right]$ & 11.2 & 11.9 & 11.2 & 11.9 & 11.3 & 11.8 & 11.2 & 11.5 \\
\hline $\begin{array}{c}\text { No. } 10 \mathrm{~g}: 10^{-3}[1] \\
\sigma_{\max }=130 \mathrm{MPa}\end{array}$ & 118 & 110 & 195 & 196 & 122 & 114 & 194 & 187 \\
\hline $\begin{array}{c}N_{0} \cdot 20 \cdot 10-3[1] \\
\sigma_{\max }=190 \mathrm{MPa}\end{array}$ & - & - & - & - & 578 & 433 & - & - \\
\hline
\end{tabular}




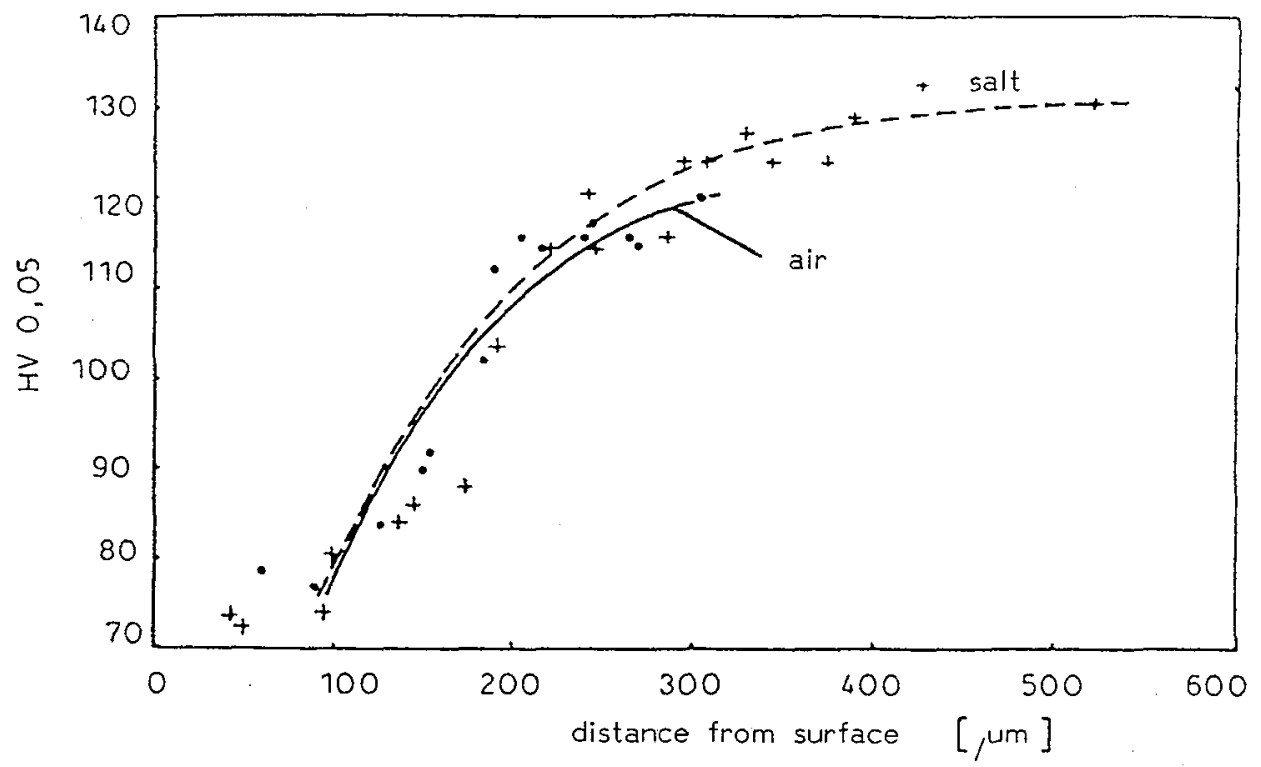

Fig. 1 - Microhardness curve as a function of the distance from extrusion surface - effect of different annealing medium on microhardness of the surface layer - specimens treated at $530^{\circ} \mathrm{C}$ for 10 hours, $0 \%$ stretching.

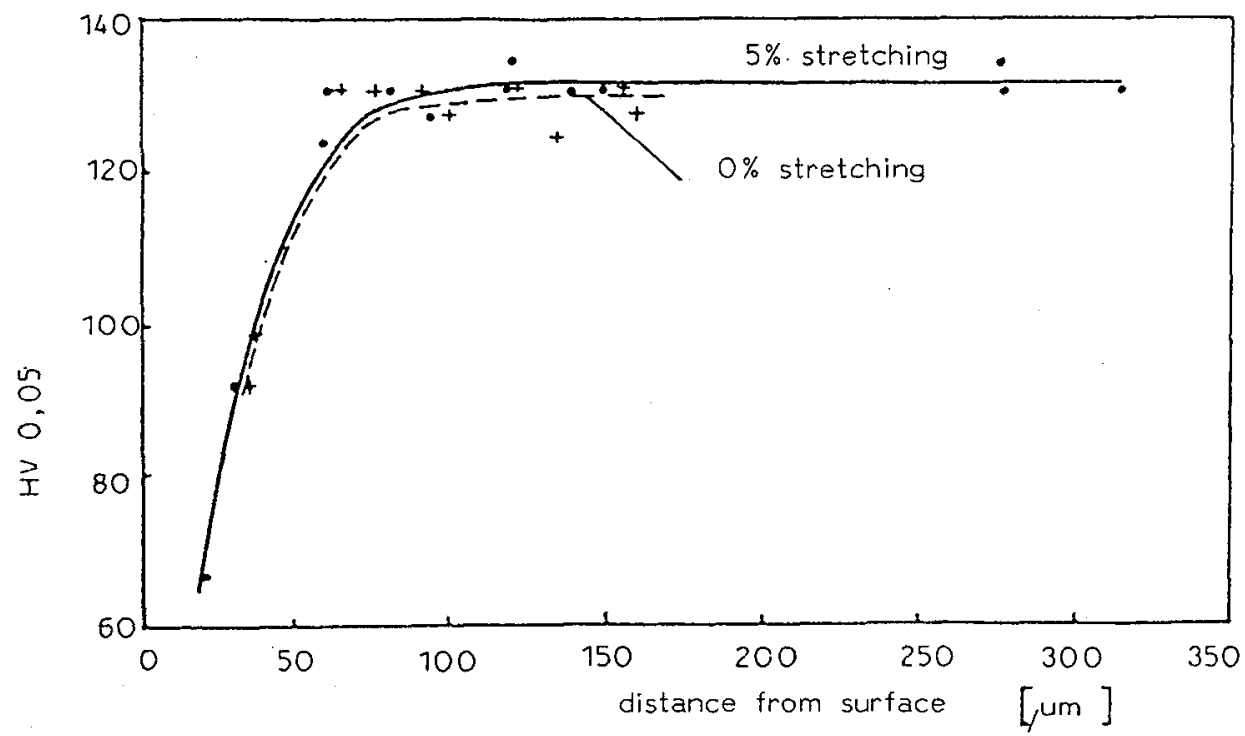

Fig. 2 - Microhardness curve as a function of the distance from extrusion surface - effect of deformation level on microhardness of the surface layer - specimens treated at $530^{\circ} \mathrm{C}$ for $20 \mathrm{~min}$. in air. 


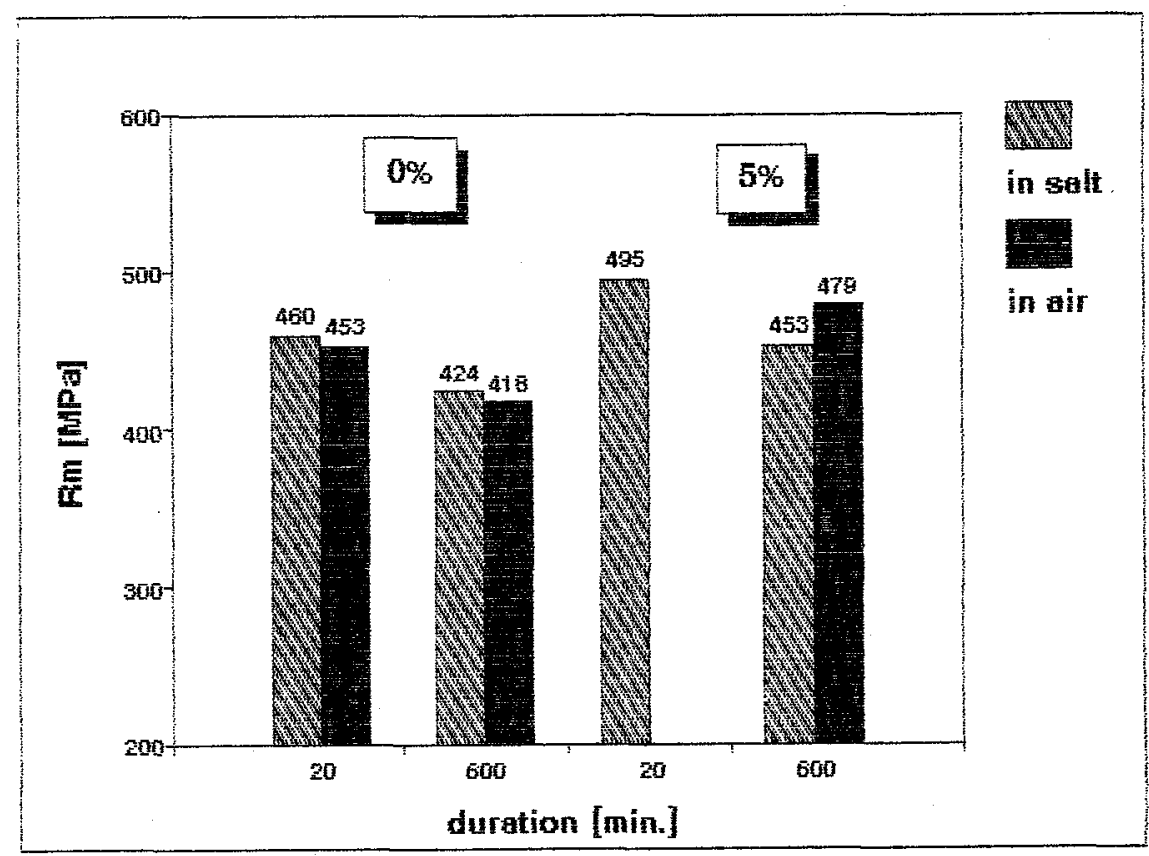

a) Bar graph of strength for the different treatment variants

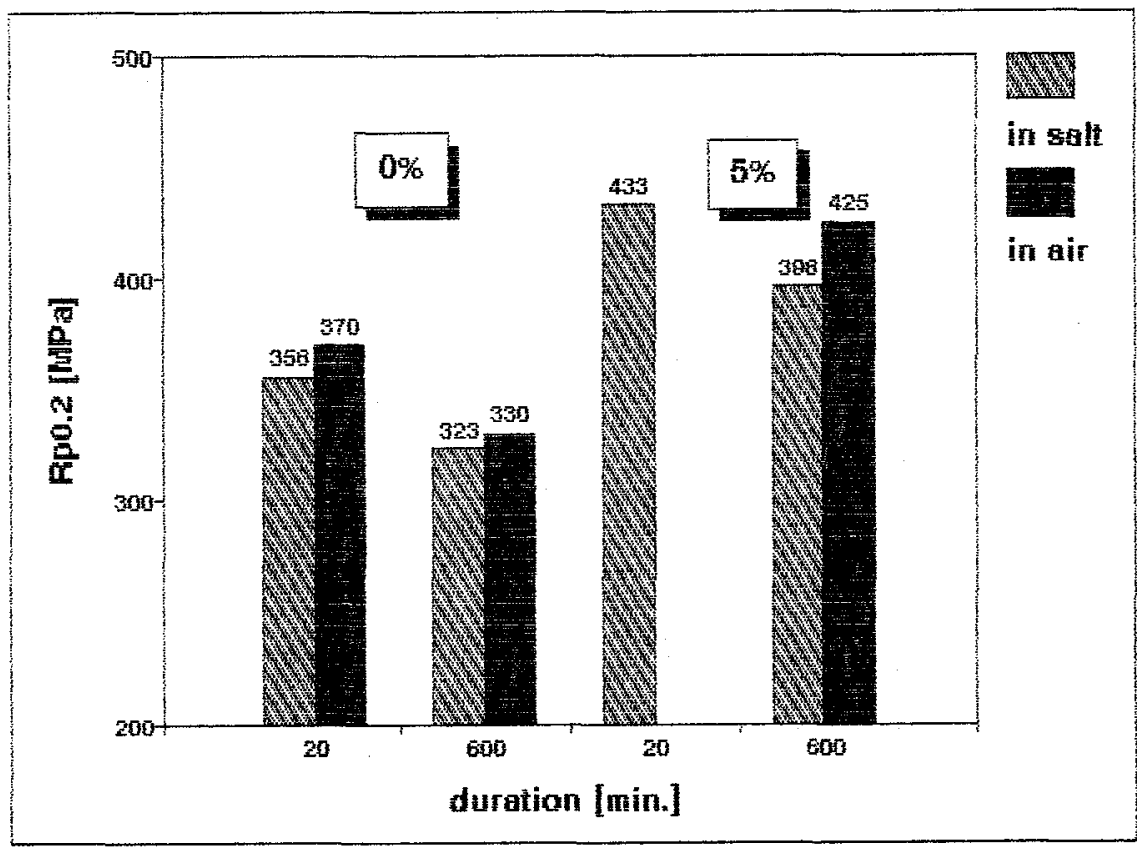

b) Bar graph of yield stress for the different treatment variants Fig. 3 - Effect of heat treatment characteristics on: a) Strength $\mathrm{R}_{\mathrm{m}}$; b) yield stress Rpo.a. 


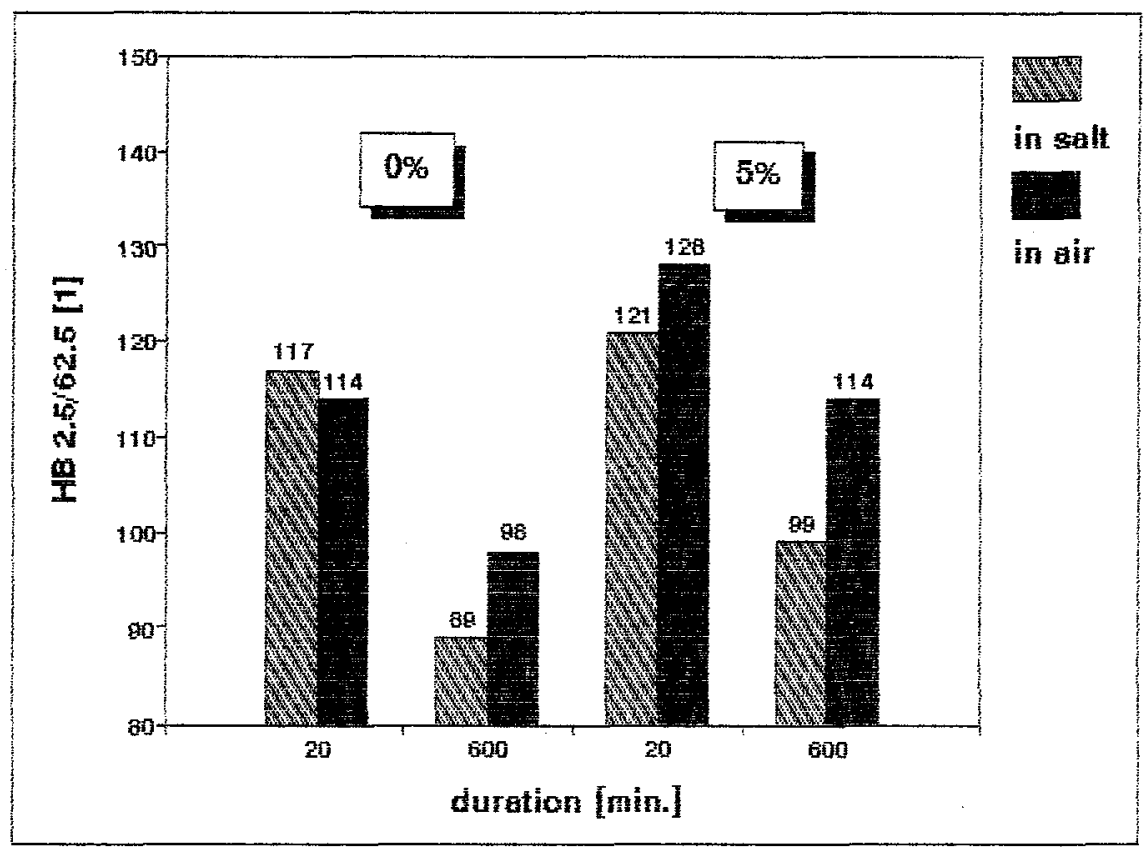

a) Bar graph of hardness for the different treatment variants

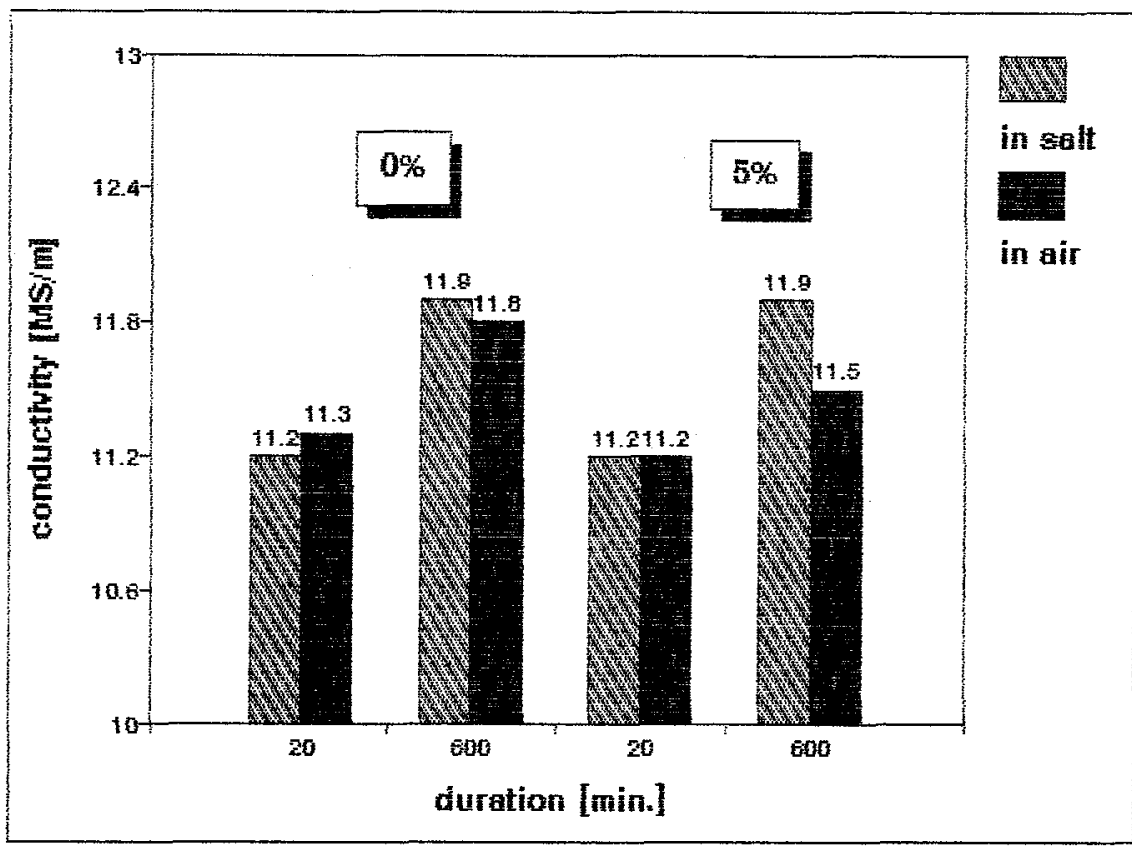

b) Bar graph of conductivity for the different treatment variants

Fig. 4 - Effect of heat treatment characteristics on: a) hardness $\mathrm{HB}$; b) electrical conductivity. 


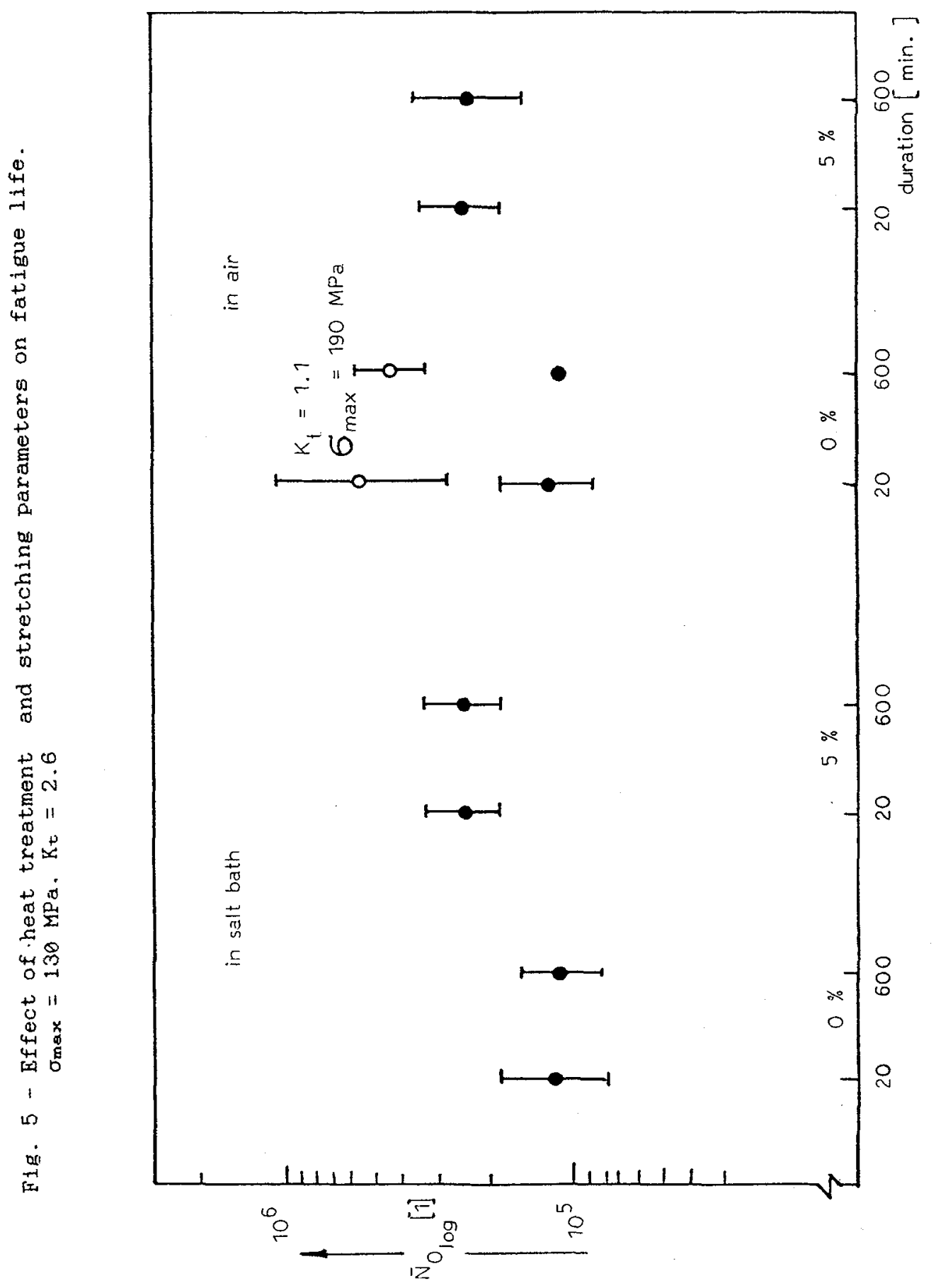

